\title{
Conference Paper \\ The Declining Endangered Roan Antelope Population in Kenya: What Is the Way Forward?
}

\author{
Johnstone K. Kimanzi and Jennifer N. Wanyingi \\ Department of Wildlife Management, University of Eldoret, P.O. Box 1125, Eldoret 30100, Kenya \\ Correspondence should be addressed to Johnstone K. Kimanzi; kimanzijo@yahoo.com
}

Received 9 September 2013; Accepted 28 October 2013; Published 20 January 2014

Academic Editors: A. Keller and E. Torrents

This Conference Paper is based on a presentation given by Johnstone K. Kimanzi at "1st International Conference on Natural Resources, Conflicts and Peace" held from 25 July 2012 to 28 July 2012 in Karatina, Kenya.

Copyright (C) 2014 J. K. Kimanzi and J. N. Wanyingi. This is an open access article distributed under the Creative Commons Attribution License, which permits unrestricted use, distribution, and reproduction in any medium, provided the original work is properly cited.

\begin{abstract}
The roan antelope, endemic to Africa, is drastically declining in Kenya and most of its range throughout Africa. Extensive research on roans in South Africa has not provided effective remedial management actions. The solution to Kenya's roans will come from detailed research in Kenya. This paper reports an on-going research on "mapping and modelling the roan antelope population and habitat in Ruma National Park, Kenya." The research is employing the state-of-the-art techniques in modelling and geographic information systems (GIS). Preliminary findings indicate that (i) the roan population has declined to 45 animals; (ii) the roans' home range changes (a) with any slight change in surface water and/or rainfall frequency and (b) between and within seasons (dry and wet); and (iii) the roans' behaviour implies possibilities of poaching. Among other interventions, establishment of a roan sanctuary (with intensive active management) in Ruma N. Park seems to be the best way forward.
\end{abstract}

\section{Introduction}

The roan antelope endemic to Africa was formerly one of Africa's most widely distributed antelopes found essentially throughout the African savannas, where water was adequate [1]. However, today they occur in small scattered groups over most of their range in the savannas of Africa. Although the roans are currently classified by the IUCN [2] as of "Least Concern," if the present trends continue, the roan antelope's status may eventually decline to threatened status as it disappears from large parts of its current range due to poaching and loss of habitat to the expansion of settlement. It is worth noting that in 1996 the same species was listed in the IUCN red list [3] as threatened and its survival dependent on active conservation measures.

The roan antelope distribution range is now drastically reduced throughout Africa and the species is faced with the risk of extinction. The roan antelope got locally extinct in Serengeti National Park in Tanzania [4], and has recently been reported to be locally endangered in South Africa's
Kruger National Park [5] and Nylsvley Nature Reserve [6]. In Kenya the roan antelope got locally extinct in the famous Masai Mara National Reserve [7] and is now critically locally endangered in Ruma National Park, which is the only place where the remaining roan population is found [8]. The roan population in this park has declined from 202 animals in 1976 to the current 45 individuals. This is of serious concern to the park management because a population of less than 50 roan antelopes is not considered viable according to population genetic criteria [9]. The problem is made even worse by the fact that there were only 22 roans in 1996 and thus the surviving 45 individuals have only the genetic diversity of their 22 ancestors. The park authorities need to act fast to halt further decline and promote population recovery back to healthy levels, before stochastic processes cause genetic loss and amplify demographic variability [5].

Many studies have been done on roan antelopes in Africa to identify the factors that cause their decline and come up with means of mitigating their effects. However, despite of much research over the last three decades [5, 9-11], the roan 
habitat requirements and the decline causal factors have not yet been fully understood. This is evidenced by the lack of adequate measures to halt roan population declines at least in the protected areas researched. Many hypotheses have been put forward to explain the roan decline including habitat deterioration and disturbances, hunting and poaching, agricultural encroachment, predation, competition with other grazers, veterinary fences, and diseases among others. However, most of the causes identified seemed to be sitespecific and cannot be applied generally to areas outside the study area. For instance, Harrington et al. [5] identified the factors causing roan decline in Kruger National Park to be competition with zebra and wildebeest and predation from lions. These factors are not applicable in Ruma National Park because the park does not have zebras, wildebeests, and lions. Also, these studies were mainly conducted on the South African subspecies (Hippotragus equinus equinus) as opposed to the East African endemic subspecies (H.e. langheldi) [12], which is studied in this research.

Due to their dwindling numbers, the roan antelopes in Kenya may soon be subjected to such manipulative procedures as translocation and captive breeding in a bid to save them. Prior to these interventions, research is necessary to come up with causal factors behind the decline and habitat requirements of the roan antelopes. In 1970, a group of 37 roans were translocated from Ithanga Hills Ranch to Shimba Hills National Reserve in Kenya [13] but they reduced to 12 within five years [9] and they got locally extinct by 1985 [14]. The causal factors leading to their extinction are still not well known. Hence without proper detailed research, translocations of roan will continue to be unsuccessful.

Mapping of detailed roan habitat in Ruma National park with high accuracy is vital to help the Park managers and planners in zoning and ensuring core areas of the roan home range are protected as well as in monitoring the effect of different management practices on roan habitat change.

It is anticipated that the successful completion of this study and implementation of its findings will halt further roan decline and promote quick population recovery. With the Ruma N. Park being in the Western Kenya tourist circuit, this will boost tourist flow into Ruma N. Park to see the endemic species of roan. In the long term, this will lead to poverty reduction in the local communities surrounding the park through the tourism industry in particular and also promote the local and national economy in general. This study will contribute towards Kenya's achievement of two vital Millennium Development Goals (poverty reduction and environmental sustainability).

\section{Materials and Methods}

2.1. Roan Population and Distribution. The past population size and distribution of the roan antelope in Kenya have been obtained from the Department of Resource Survey and Remote Sensing (DRSRS) and Kenya Wildlife Service (KWS). For the present roan population in Ruma N. Park, roan antelopes have been counted simultaneously in 10 animal counting blocks with assistance from the Park staff.
The 10 blocks are permanently marked and have been used in the past as animal counting blocks.

Data on roan home range is being collected using both continuous monitoring and point location sampling methods as described by Kenward [15] for the dry and wet seasons separately. The point sampling is better than continuous monitoring because it yields independent location records. The continuous monitoring method has only been used in a pilot study and its data analyzed using autocorrelation analysis and timetabling to decide on the optimal interval for point sampling method. Autocorrelation analysis tests for independence of location records, which is necessary to yield robust analyses. Kenward [15] (2001) reports how Swihart and Slade [16] used Schoener's [17] index, $V=t^{2} / r^{2}$, to test time to independence (TTI), where $t^{2}$ is the mean squared distance between consecutive location records and $r^{2}$ is the mean squared distance from each location to the arithmetic mean coordinates of all locations. The $t^{2}$ and $r^{2}$ are computed using the following formulas:

$$
\begin{aligned}
t^{2} & =\frac{1}{m} \sum_{i=1}^{m}\left(X_{i+1}-X_{i}\right)^{2}+\frac{1}{m} \sum_{i=1}^{m}\left(Y_{i+1}-Y_{i}\right)^{2}, \\
r^{2} & =\frac{1}{n-1} \sum_{i-1}^{n}\left(X_{i}-\bar{X}\right)^{2}+\frac{1}{n-1} \sum_{i=1}^{n}\left(Y_{i}-\bar{Y}\right)^{2},
\end{aligned}
$$

where $m$ is the number of pairs of successive observations ( $m=n-1$ when all pairs are used), $X$ and $Y$ are the coordinates of the locations, and $i$ denotes the order in which observations were collected. The practical minimal interval for point sampling is when $V$ is at least 1 [15].

\subsection{Vegetation Mapping and Roan Habitat Characteristics.} Vegetation mapping is being done based on the method described by Janssen and Huurneman [18], which involves six major steps: preprocessing satellite images, visual image interpretation, field data collection (ground truth), field data analysis, digital image classification, and map accuracy assessment. Roan habitat characteristics data are being collected for both dry and wet seasons. Six readily available landsat imageries for 1973, 1986, 1989, 2000, 2003, and 2005 will be analyzed for vegetation mapping.

Ground truth is being conducted using stratified random sampling technique but a pilot vegetation survey was performed first to help in proper implementation of the sampling design. In each stratum, 50 circular sample plots have been selected at random and the $X$ and $Y$ coordinates of their centres recorded in a Global Position System (GPS) to aid in locating them in the field. The circular plots differ in size depending on the vegetation type and physiognomy. For each selected sample plot, the following data is collected: \% cover of different vegetation layers (i.e. trees, shrubs, herbs, and grass), average height per vegetation layer, \% cover and average height of dominant plant species per vegetation layer, and \% cover of bare ground or water. Vegetation canopy cover and height data are collected via estimation. Before the collection of these data, the Forest Spherical Densiometer and the Sunto Hypsometer were used to train the researcher 
the estimation of vegetation canopy cover and vegetation height, respectively.

2.3. Factors Causing Population Decline of Roan Antelopes. Data on the factors causing population decline of the roan antelopes is being obtained via secondary data from literature and records in Ruma National Park. This includes data on population of other grazers in the park, soil distribution, annual rainfall, distribution of surface water, and density of snares in the park. The density of snares in the park is being measured using stratified random sampling design adopted from Wato et al. [19] to test whether snare placement is dependent on roan presence and/or vegetation type. The park has been divided into three strata: roan home range, roan nonhome range, and the area around park gates and outposts, with each stratum measuring $2 * 5 \mathrm{~km}^{2}$ and cutting across various vegetation types representative of the study area. In each stratum, 25 equal grids of $200 * 2000 \mathrm{~m}^{2}$ have been laid. Five grids have been selected from each stratum at random and subdivided into 10 equal quadrats measuring $200 * 200 \mathrm{~m}^{2}$. A total of 150 quadrats constitute the sampling sites where snare counts are being done with total area coverage of $20 \%$ in each quadrat.

\section{Results}

The on-going fieldwork in Ruma National Park is aimed at collecting 5 types of primary data (roan population and distribution, vegetation, snares, surface water, and soil) and 3 types of secondary data (digital elevation data, rainfall, and population of other grazers in the park). So far substantial data has been collected on digital elevation, rainfall, population of other grazers, and surface water resources. The data collected include $20 \mathrm{~m}$ resolution contours for the whole park, monthly rainfall data from 1970 to 2007, census data of other grazers (buffalo, topi, impala, Jackson's hartebeest, and waterbuck) in the park from 1976 to 2008, and coordinates and linear features of surface water resources in the park. Few amounts of data have been collected on roan population and distribution and vegetation.

3.1. The Roan Population. Collection of secondary data on the past roan population in Ruma National Park has revealed that the population declined continuously in 20 years from 202 individuals in 1976 to 22 roans in 1996 but has increased slightly to the current 45 remnants (Figure 1). Analysis of these data using polynomial regression shows an overall population decline.

Counting of roans in 10 counting blocks combined with tracking the roans for three months has identified the current roan population in the park to be 45 individuals. The roans are in 4 breeding groups, 1 bachelor herd, and 2 lone males. A detailed age structure and group sizes of the roan population are given in Table 1. The group sizes presented here are just averages because the group sizes were dynamic with changes being more pronounced during the wet season than the dry season. The male to female sex ratios for the adults and subadults are around $1: 3$ and $1: 1$, respectively.
TABLE 1: Current roan population in Ruma National Park, Kenya.

\begin{tabular}{|c|c|c|c|c|c|c|}
\hline \multirow{3}{*}{ Group } & \multirow{3}{*}{ Size } & \multicolumn{5}{|c|}{ Age structure } \\
\hline & & \multicolumn{2}{|c|}{ Adult } & \multicolumn{2}{|c|}{ Subadult } & \multirow{2}{*}{$\begin{array}{c}\text { Young } \\
\text { (Unsexed) }\end{array}$} \\
\hline & & Male & Female & Male & Female & \\
\hline I & 14 & 1 & 10 & 1 & 1 & 1 \\
\hline II & 12 & 1 & 5 & 1 & & 5 \\
\hline III & 10 & 1 & 8 & & 1 & \\
\hline IV & 5 & 1 & 4 & & & \\
\hline $\mathrm{V}$ & 2 & 2 & & & & \\
\hline Lone & 1 & 1 & & & & \\
\hline Lone & 1 & 1 & & & & \\
\hline Total & 45 & 8 & 27 & 2 & 2 & 6 \\
\hline
\end{tabular}

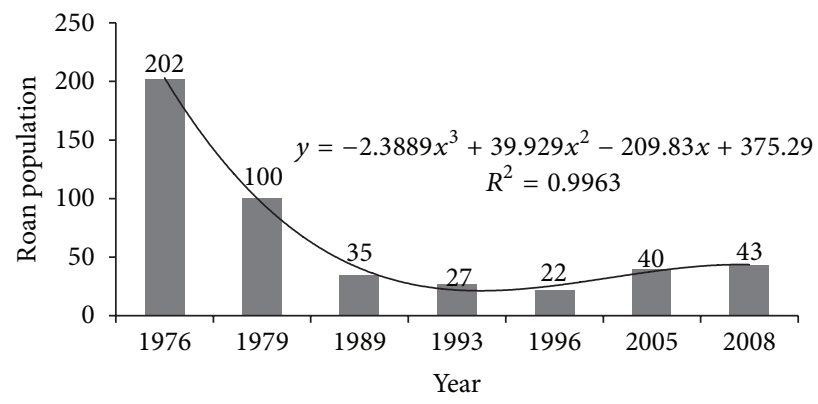

Figure 1: Roan population changes in Ruma N. Park: 1976-2008.

TABLE 2: Schoener's indices for roan antelopes in Ruma N. Park.

\begin{tabular}{lcccc}
\hline Time interval & 10 minutes & 30 minutes & 1 hour & 2 hours \\
Schoener's $(V)$ index & 0.03 & 0.14 & 0.57 & 1.18 \\
\hline
\end{tabular}

3.2. Roan Home Range Changes. The tracking of roan antelopes at 10-minute intervals for several whole days (7.00 a.m. to 7.00 p.m.) revealed that the roans are mainly active in the morning (7.00 a.m. to 11.00 a.m.) and late afternoon (4.00 p.m. to 7.00 p.m.). They spent the rest of the time from 11.00 a.m. to 4.00 p.m. resting since the sun is very hot during this time. Testing for time of independence of the roan locations using the Schoener's [17] index indicated that at an interval of 2 hours the $V$ index was around 1, which is a recommended index value for optimal point sampling according to Kenward [15]. The details of the Schoener's [17] indices are shown in Table 2. From these preliminary observations and analysis of the roan activity budget, it was decided to make records of each group and lone male five times a day (8 a.m., 10 a.m., 1 p.m., 4 p.m., and 6 p.m.).

Preliminary results from the point location sampling indicated that the roans' home range varies between and within the dry and wet seasons. Home ranges were analyzed for two selected breeding groups of roans in the park (one group found near Nyatoto Gate and the other near Nyandenda Outpost). The illustrations show that in the two groups the roan home range areas were larger during the wet season as compared to the dry season (Figures 2 and 3). A record of the number of days it rained during the wet season was kept and used to divide the wet season home range 


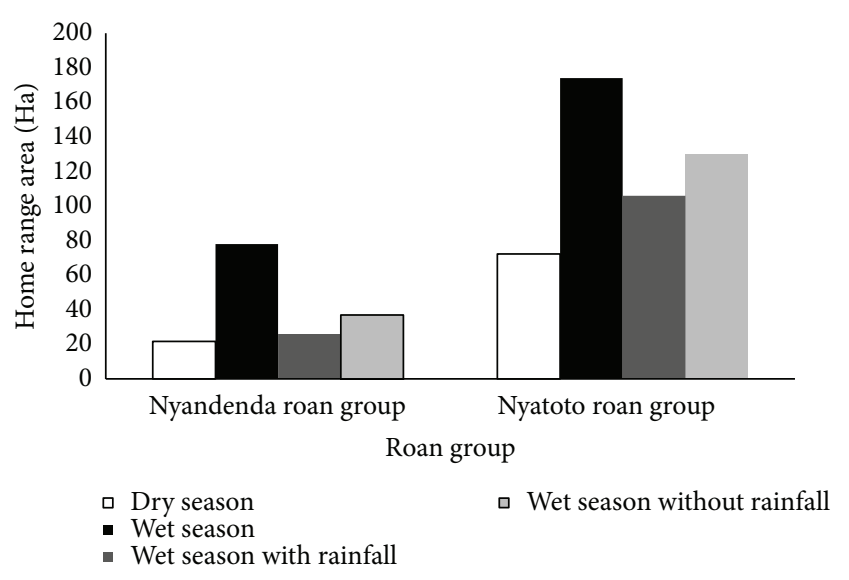

Figure 2: Home range areas for two selected roan groups in Ruma N. Park.

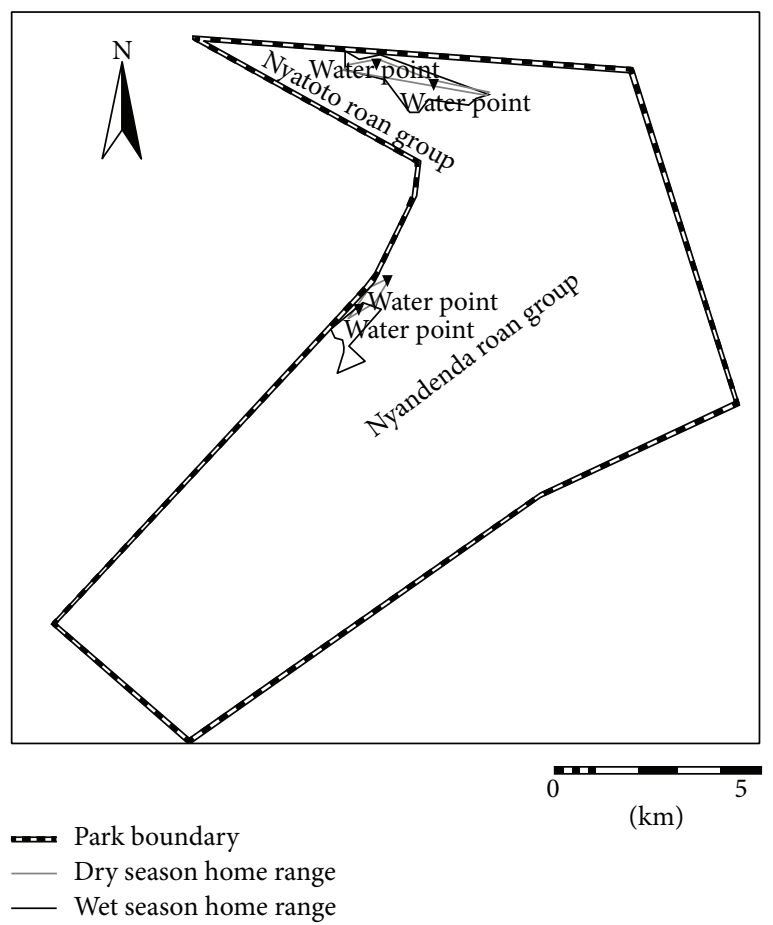

Figure 3: Dry and wet season home ranges for two selected roan groups.

into two categories: wet season with rainfall and wet season without rainfall. Analysis revealed that the home ranges were smaller during the wet season with rainfall as compared to the wet season without rainfall (Figure 4). Both the dry and wet season roan home ranges were never more than $2 \mathrm{~km}$ away from a surface water source. Also the dry season home ranges were nearer to water sources than the wet season home ranges.

3.3. The Roan Behaviour. The roans appeared disturbed by the researcher's presence during the start of data collection period but they got habituated within two weeks, when they

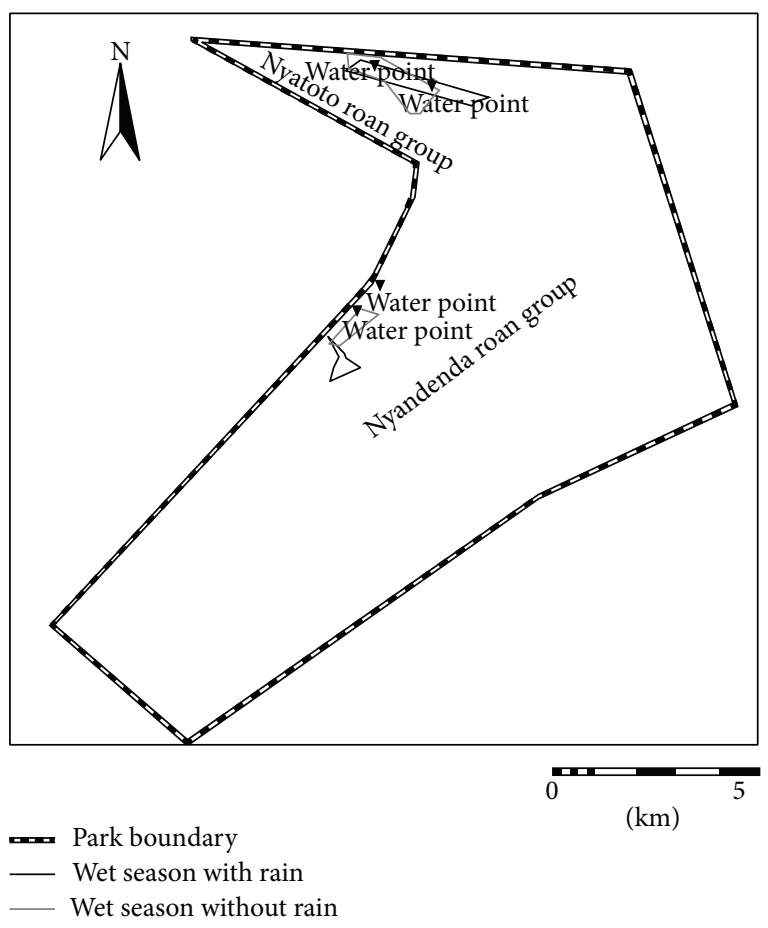

FIGURE 4: Wet season with and without rainfall home ranges for two selected roan groups.

could be approached up to a fly distance of $50 \mathrm{~m}$ without appearing disturbed. However, the roans encountered near thick vegetation (shrubland and forest habitats), park boundary, or public roads looked scared and afraid unlike those found in grassland habitats and near the rangers' outposts. The same group of roans exhibited different behaviors depending on the place and habitat where they were encountered.

3.4. Vegetation. Preliminary vegetation survey and characterization have identified the following 10 vegetation classes based on percentage canopy cover, dominant species, and vegetation height: open grassland, dwarf shrub grassland, sparsely shrubby grassland, shrubby grassland, thin-wooded grassland, wooded grassland, woodland, shrubby woodland, shrubland, and forest. It is anticipated that 50 samples of each vegetation class will be collected. The roan antelopes have been located mainly in the grassland habitats. The roan group, whose home range covered both grassland habitats with soft green grass (as aftermath of fire outbreaks) and tall rough dry grass, was mainly observed feeding on the short green grass.

3.5. Rainfall. Analysis of monthly rainfall data for over 30 years for Ruma N. Park indicated that the park experienced drought in 1999-2000 and below average rainfall in 19861987 and 2003-2005 (Figure 5). During the 1986-1987 below average rainfall period, the roan population declined, but during the drought of 1999-2000 and below average rainfall of 2003-2005, the roan population slightly increased. Overall comparison of change in rainfall with change in roan 


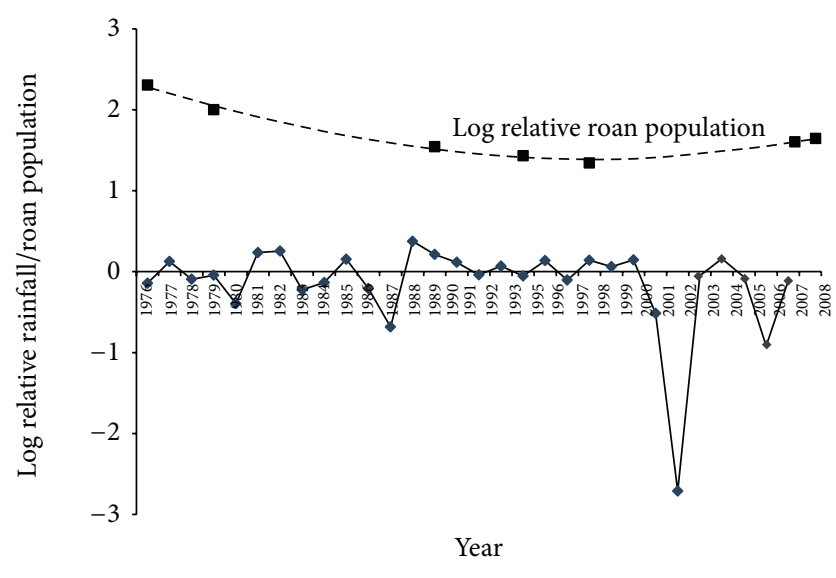

FIGURE 5: Comparison of log relative rainfall and roan population: 1976-2008.

population using logarithmic transformation and descriptive statistics did not reveal any direct association. However, the comparisons could not be done adequately because there were very few records for the roan antelope as compared to rainfall records.

\section{Discussion and Conclusions}

The roan population in Ruma National Park for the last over 3 decades shows an overall declining trend. Since 1989 the roan population has been below 50 individuals, which might be below the minimum viable population and thus unable to recover to healthy levels. This is supported by Soule's [20] conclusion that a population of less than 50 roan antelopes is not viable according to the population genetic criteria. The current roan population age structure as well as an extrapolation using a polynomial regression model (which very strongly fits the current data set; $R^{2}=0.9964$ ) predicts further population decline in the future if there is no intervention. Since the roan species is considered to be conservation dependent [3], human intervention by park authorities is urgently needed to jump-start the population recovery process. The interventions can include (i) reintroduction of other individuals from other countries to boost the numbers and counter the effect of inbreeding; (ii) provision of sufficient surface water, especially during the dry season; (iii) provision of security through increased routine patrols by rangers; and (iv) captive breeding to raise a seed population for reintroduction into known roan ranges in Kenya.

The change in male : female sex ratio with a bias towards females from subadult to adult suggests that more adult males may be dying than adult females. This might be due to the benefits the females reap from group living whereas the adult lone males are at more risks. This hypothesis needs more data to be tested. However, the proper analysis of the past roan population dynamics is limited by the lack of systematic and reliable population data records. The roan groups changed and split more often during the wet season than the dry season maybe because the resources are more readily available in wet season but limited resources during dry season called for concrete group living to enhance survival.

The roans' home range varied between and within the dry and wet seasons. The dry season home ranges were smaller than wet season home ranges because the roans are water dependent and need to be near surface water sources, which are scarce, limited, and confined during the dry season but more abundant and readily available in the wet season. Literature on roan occurrence in Africa supports this argument by maintaining that roans were abundant in areas with plenty of water [1]. However, wet home ranges with rainfall were smaller than wet home ranges without rainfall. This was because when there is plenty of rainfall and thus availability of several temporary pools of water, the roans do not need to move for long distances but when the rains stop for some time and the temporary pools of water dry out, the roans have to move for water in the permanent and few water points. Consequently the wet home ranges without rainfall are expanded and elongated towards the water points and thus become larger than the wet home ranges with rainfall. This indicates that the roans are not only extremely water dependent but also highly sensitive to slight changes in surface water sources. With one of the effects of global climatic change being unpredictable and unreliable rainfall, the park authorities need to be on high alert to provide sufficient surface water to the roans when the rains are inadequate. The roan home range areas for both the dry and wet seasons were less than $2 \mathrm{~km}^{2}$. These areas are small compared with home range areas of at least $5 \mathrm{~km}^{2}$ recorded by Allsopp [9] in the park in 1970s. This maybe as a result of the short period used in data collection or due to different methods used in estimating the roan home range areas.

The same group of roans exhibited different behavioural habits depending on the place and habitat where they were encountered. The roan behaviour is negatively affected by proximity to park boundary, public roads, unfamiliar persons, and thick habitats, which indicates possibilities of poaching or animal harassment by people from outside the park. The park is surrounded by intense human settlement, implying that the fear exhibited by roans near the park boundary may be an aftermath of past poaching experiences with the surrounding community. There is a public main road and two foot paths passing through the park, where roans encountered near them appear scared suggesting possibilities of poaching in these spots in the past. Snares for trapping animals in the park are mainly laid in thick habitats such as bushland and forests; hence roans appeared alarmed when spotted in these habitats due to past experiences of being trapped. The roans encountered near rangers' outposts appeared calm and undisturbed, implying a feeling of sense of security from the rangers as opposed to roans encountered by unfamiliar persons. During the data collection period, poaching has been evidenced by removal of 29 snares in thick habitats and on scattered trees in grassland habitats within the park. From 2003 up to 2006 a total of 528 snares were collected in the park by the Youth for Conservation [21]. Also 138 snares were collected by staff and students from Moi University in 1993. Roans bearing signs of snares were also sighted in the park as early as 1971 by Allsopp [9]. 
The roan antelopes have been observed utilizing grassland habitats and especially those with soft green grass which result from effects of fire outbreaks. Although there is no prescribed burning program in the park, fire outbreaks occur every year during the dry season. Prescribed burning which used to be practiced in the past needs to be revived to promote the growth of healthy grass, especially in the roan home ranges in the park.

Comparisons between changes in roan antelope population and rainfall within the park did not reveal any direct relationship. However, these comparisons could not be done adequately because there were very few records for the roan population as compared to the rainfall records. If more roan population data are acquired, data relationships may be analyzed to yield more reliable results.

\section{Recommendations}

The park authorities should implement intervention approaches to promote recovery of the roan population to healthy levels. These approaches can include establishment of a roan sanctuary within the Ruma N. Park. In this sanctuary, there should be (i) prescribed burning program to promote growth of healthy grass throughout the year, (ii) provision of sufficient well distributed surface water through digging more bore holes and dams, especially during the dry season, (iii) provision of security through increased routine patrols by rangers, (iv) controlled number of grazers within the sanctuary enclosure, (v) proper complete fence, and (vi) no roads or footpaths within the sanctuary.

The East African roan subspecies (H.e. langheldi) should be reintroduced into the park from other countries such as Tanzania. This will boost the roan numbers to a value beyond the minimum viable population and also increase the genetic variability. Research should be conducted to assess possibility of reintroducing roans in Masai Mara National Reserve (former roan range) in a roan sanctuary with conditions as mentioned above.

The current community public main road and footpaths passing through the park need to be closed immediately and be diverted outside the park. This will reduce the chances of poachers entering the park with the pretext of being passersby. The current road network also needs to be diversified to make it easy for patrols and future research as well as promote tourist satisfaction.

\section{Conflict of Interests}

The authors declare that there is no conflict of interests regarding the publication of this paper.

\section{References}

[1] J. Kingdom, East African Mammals: An Atlas of Evolution in Africa, University of Chicago, Chicago, Ill, USA, 1984.

[2] IUCN, "IUCN Red List of Threatened Species. Version 2010. 4," 2010, http://www.iucnredlist.org.

[3] IUCN, Red List of Threatened Animals, IUCN, Gland, Switzerland, 1996.
[4] K. Campbell and M. Borner, "Population trends and distribution of Serengeti herbivores: implications for management," in Serengeti II, A. R. E. Sinclair and P. Arcese, Eds., pp. 117-145, University of Chicago Press, Chicago, Ill, USA, 1995.

[5] R. Harrington, N. Owen-Smith, P. C. Viljoen, H. C. Biggs, D. R. Mason, and P. Funston, "Establishing the causes of the roan antelope decline in the Kruger National Park, South Africa," Biological Conservation, vol. 90, no. 1, pp. 69-78, 1999.

[6] W. G. Dörgeloh, "A draft habitat suitability model for roan antelope in the Nylsvley Nature Reserve, South Africa," African Journal of Ecology, vol. 39, no. 3, pp. 313-316, 2001.

[7] A. R. E. Sinclair and P. M. Arcese, Serengeti II: Dynamics, Management, and Conservation of an Ecosystem, University of Chicago Press, Chicago, Ill, USA, 1995.

[8] D. Kones, The Status of Kenya's Roan Antelope (Hippotragus equinus-Langheldi) in Ruma National Park 1974-2005, Kenya Wildlife Service (KWS), Nairobi, Kenya, 2005.

[9] R. Allsopp, "Roan antelope population in the Lambwe Valley, Kenya," Journal of Applied Ecology, vol. 16, pp. 109-115, 1979.

[10] R. Kröger and K. H. Rogers, "Roan (Hippotragus equinus) population decline in Kruger National Park, South Africa: influence of a wetland boundary," European Journal of Wildlife Research, vol. 51, no. 1, pp. 25-30, 2005.

[11] D. E. Wilson and S. M. Hirst, Ecology and Factors Limiting Roan and Sable Antelope Populations in South Africa, vol. 54 of Wildlife Monographs, 1977.

[12] D. L. Alpers, B. J. Van Vuuren, P. Arctander, and T. J. Robinson, "Population genetics of the roan antelope (Hippotragus equinus) with suggestions for conservation," Molecular Ecology, vol. 13, no. 7, pp. 1771-1784, 2004.

[13] A. Parkinson, “The roan story," Africana, vol. 4, no. 9, pp. 15-34, 1972.

[14] M. W. Litoroh, Preliminary Inventory on Animal Ecological Status in Shimba Hills National Reserve, Kenya Wildlife Service (KWS), Nairobi, Kenya, 1989.

[15] R. E. Kenward, Manual for Wildlife Radio Tagging, Academic Press, London, UK, 2001.

[16] R. K. Swihart and N. A. Slade, "Testing for independence of observations in animal movements," Ecology, vol. 66, no. 4, pp. 1176-1184, 1985.

[17] T. W. Schoener, "An empirically based estimate of home range," Theoretical Population Biology, vol. 20, no. 3, pp. 281-325, 1981.

[18] L. L. F. Janssen and G. C. Huurneman, Eds., Principles of Remote Sensing, ITC, Enschede, The Netherlands, 2001.

[19] Y. A. Wato, G. M. Wahungu, and M. M. Okello, "Correlates of wildlife snaring patterns in Tsavo West National Park, Kenya," Biological Conservation, vol. 132, no. 4, pp. 500-509, 2006.

[20] M. E. Soule, "Thresholds for survival: maintaining fitness and evolutionary potential," in Conservation Biology: An Evolutionary-Ecological Perspective, M. E. Soule and A. Wilcox, Eds., pp. 151-169, Sinauer Associates, Sunderland, UK, 1980.

[21] Youth for Conservation, A Status Report on Snares in Ruma National Park, Youth for Conservation (YFC), Nairobi, Kenya, 2006. 

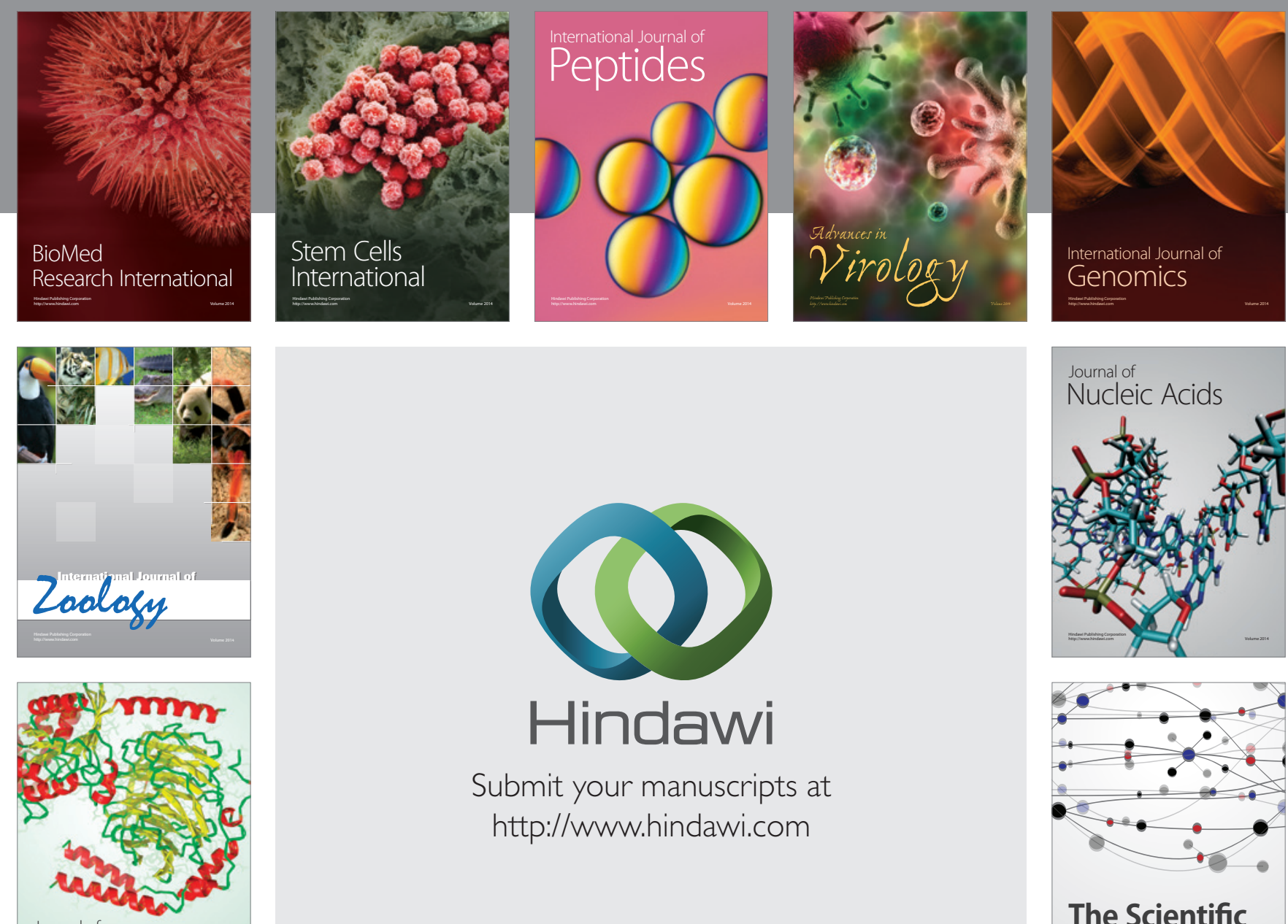

Submit your manuscripts at

http://www.hindawi.com

Journal of
Signal Transduction
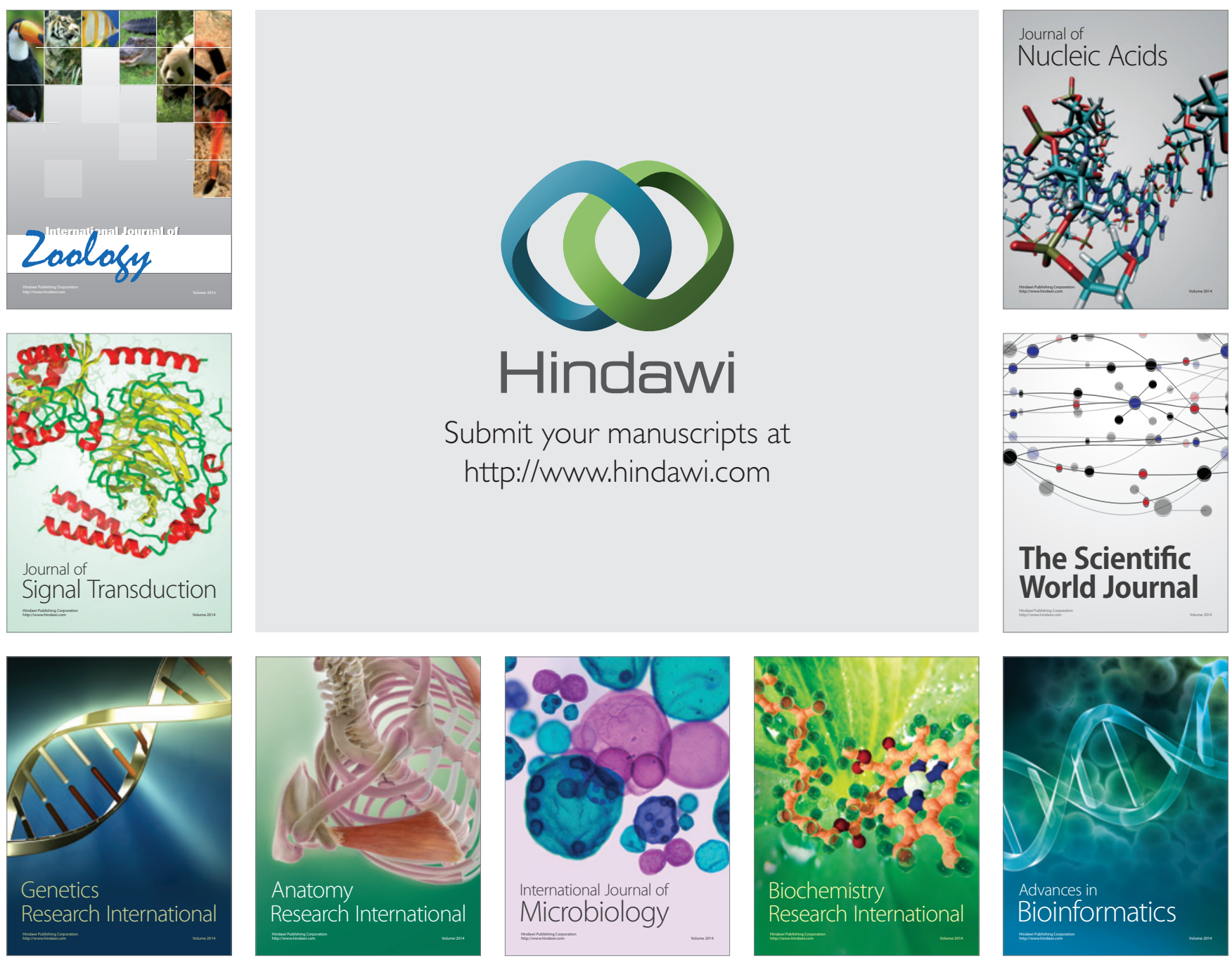

The Scientific World Journal
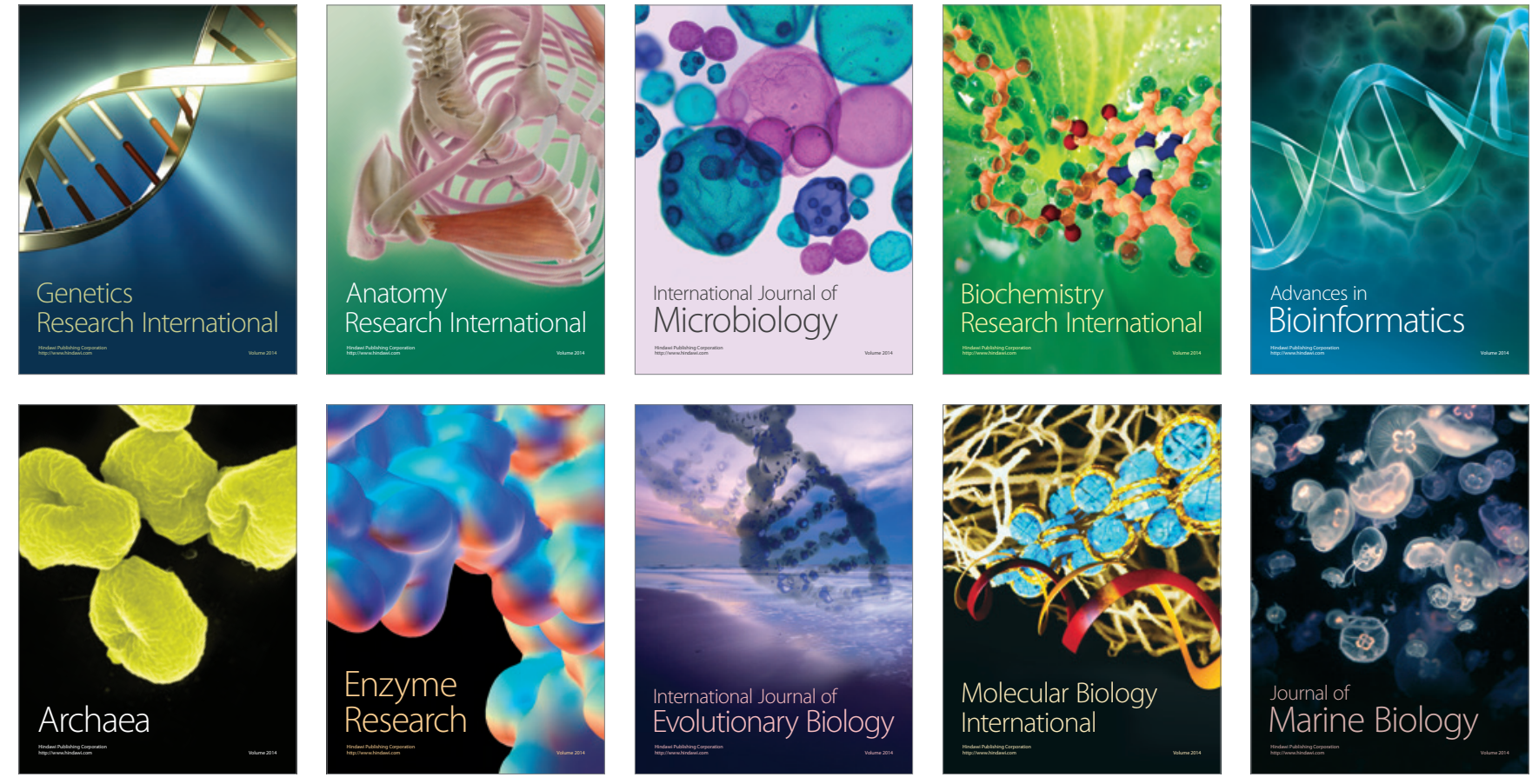